\title{
A arte a serviço da formação moral: o Elogio a Richardson
}

Christine Arndt de Santana

FANESE / Sergipe 

Ao se iniciar a leitura de um texto, a postura a ser adotada pelo leitor/espectador ${ }^{1}$ vai depender dos objetivos que ele possui. Nesse sentido, seria possível afirmar que a leitura da apologia a Richardson escrita por Diderot pode ser feita a partir de duas perspectivas diferentes: a do prazer e a da instrução; a do dulce e a do utile. A maestria com a qual o Philosophe escreve sua poética sobre o romance e as técnicas de Richardson que aplica ao seu próprio texto permitem considerar esse panegírico também como uma obra literária; Diderot consegue incutir em seu leitor/espectador a dúvida sobre a veracidade de alguns fatos descritos, levando-o a se questionar até que ponto o que está exposto é real ou fantasia. E como observa Orhan Pamuk² (2011. p. 31), fazer esse exercício de perguntar quais partes se baseiam em experiências reais e quais são imaginadas é um dos prazeres que um texto literário pode nos causar. O Elogio não é um romance, mas extrapola os limites da sua poética.

Diderot iniciou seu texto evocando o conceito de romance até o século XVIII com o objetivo de contrapor Richardson ao que se denomina romance, e mostra que essas manifestações artísticas não se coadunam num mesmo conjunto.

Por romance entendia-se até agora um tecido de acontecimentos quiméricos e frívolos, cuja leitura era perigosa para o gosto e para os costumes. Eu desejaria muito que se encontrasse um outro nome para as obras de Richardson, que elevam o espírito, que tocam a alma, que respiram por toda a parte o amor ao bem, e que se denominam também romances (Diderot, 2000, p. 16).

$1 \mathrm{O}$ uso do binômio leitores/espectadores se dá em razão do fato de que, para Diderot, o realismo deve ser levado tão a sério em uma obra (literária, dramática ou mesmo plástica) que ele elenca alguns recursos importantes para que o autor tenha o efeito desejado. Nas artes plásticas, assim como no drama e na literatura, o uso de "quadros", (conceito diderotiano para classificar a descrição das cenas) assim como de pantomimas, na literatura e no drama, ajuda quando se deseja colocar a moral em prática. Nesse sentido, o leitor torna-se, em razão desses "quadros" e pantomimas, um espectador do que é narrado.

2 Pamuk usa o termo romance e não texto literário quando desenvolve essa ideia. 
Richardson pôs em ação tudo o que fora posto em máximas por Montaigne, Nicole, Charron, La Rochefoucauld; exercitou a moral, colocou-a em prática. Para Diderot, é possível a um homem de espírito, ao ler Richardson, refazer as sentenças dos moralistas; mas esse mesmo homem, ao deparar com essas sentenças, seria incapaz de reconstituir, num percurso inverso, uma única página sequer das obras de Richardson. A ineficácia da máxima moral ocorre, segundo o autor do Elogio, porque em sendo esta máxima uma regra abstrata e geral a sua aplicação passa a ser de responsabilidade daquele que a lê; a própria regra não fornece orientação para a ação.

Ela não imprime por si mesma nenhuma imagem sensível em nosso espírito: mas aquele que age, nós o vemos, colocamo-nos em seu lugar ou a seu lado, apaixonando-nos por ou contra ele; nós nos unimos a seu papel, se é virtuoso; nós nos afastamos dele com indignação, se é injusto e vicioso. Quem é aquele a quem o caráter de um Lovelace, de um Tomlinson, não faz tremer? ( Id., ibid.).

Richardson transporta os homens, na leitura de suas obras, e leva-os a assumir um papel no enredo que se apresenta aos seus olhos. Não é possível ser um leitor/espectador sem se engajar na história, sem se intrometer nas ações das personagens, sem se envolver na progressão dos fatos, a ponto de se espantar ou indignar-se, de culpar a uns e inocentar a outros; enfim, não se lê impunemente um romance feito nesses novos moldes; não se lê impunemente Richardson. É-se tocado pelo enredo; e, ao ser tocado, o leitor/espectador transforma-se.

Ó Richardson!, a gente assume, a despeito do que se é, um papel em tuas obras, a gente se intromete na conversação, aprova, culpa, admira, irrita-se, indigna-se. Quantas vezes não me surpreendi, como acontece às crianças que são levadas a um espetáculo pela primeira vez, gritando: Não creiam nele, ele vos engana... Se fordes até lá, estais perdido. Minha 
alma era presa de uma agitação perpétua. Como eu era bom!, como eu era justo!, como eu estava satisfeito comigo mesmo! Eu estava, ao sair de tua leitura, como está um homem ao fim de um dia que ele empregou na prática do bem ( Id., ibid., p. 17)3.

E o que essa moralização furtiva, essa moral em ação torna possível? Que se conheçam inúmeras personagens e situações que irão ajudar na aquisição de experiências. Segundo Pamuk, romances têm a capacidade de revelar cores e complexidades da vida, além de fornecerem inúmeras pessoas, rostos e objetos que, na experiência estética, julgamos conhecer. ${ }^{4}$ Forster, em Aspectos do Romance, afirma que o grande mérito desse gênero é revelar a vida introspectiva das personagens, pois é bastante limitado o número de pessoas cuja existência interior e motivações é possível conhecer no curto espaço de tempo de uma vida. ${ }^{5} \mathrm{E}$ Diderot, na mesma esteira, afirma:

Eu havia percorrido no intervalo de algumas horas, um grande número de situações que a vida mais longa mal oferece em toda a sua duração. Eu tinha ouvido o verdadeiro discurso das paixões; eu tinha visto as molas do interesse e do amor-próprio em jogo de cem maneiras diversas; eu me havia tornado o espectador de uma multidão de incidentes, eu sentia que tinha adquirido experiência (Diderot, 2000, p. 17$)^{6}$.

Como saber a priori se uma determinada máxima pode ser aplicada a certa situação, sem estar sendo injusto? Como atuar numa circunstância nunca antes vivida, sem cometer um erro de ação, uma vez que não se tem nenhum evento correspondente que possa servir de exemplo? Só é possível resolver essa questão

\footnotetext{
3 O segundo grifo é nosso.

4 Cf. Pamuk, 2011.

5 Cf. Forster, 2005.

6 Grifo nosso.
} 
quando se altera a maneira de se educar moralmente os homens. A literatura, nesse sentido, deve ser entendida como o instrumento que possibilita a formação do homem, ao oferecer os exemplos, os modelos de ação, a partir do enredo de uma obra; ela é a responsável por tornar a existência suportável, pessoal, visto seu objeto ser a natureza humana. Diderot entendia assim que a obra literária deveria adotar tais procedimentos, uma vez que estes levam o leitor/espectador a se questionar em todo momento: "será isso verdade? Será isso mentira?”, em razão da ilusão causada pelo enredo.

O mundo em que nós vivemos é o lugar da cena; o fundo de seu drama é verdadeiro; suas personagens têm toda a realidade possível; suas figuras são tomadas do âmbito da sociedade; seus incidentes estão nos costumes de todas as nações civilizadas; as paixões que ele pinta são tais como eu as experimento em mim; são os mesmos objetos que as excitam, elas têm a energia que eu thes reconheço; os contratempos e as aflições são da natureza daquelas que me ameaçam incessantemente; ele me mostra o curso geral das coisas que me cercam. Sem esta arte, minha alma dobrando-se com dificuldades a vieses quiméricos, a ilusão seria apenas momentânea e a impressão, fraca e passageira (Id., ibid.)7.

Ou seja, é esse realismo que possibilita ao leitor/espectador ser tocado, e emular a ação do romance, através do que Pamuk chama de trama ${ }^{8}$. Avançando em seu panegírico, Diderot, após deter-se na verossimilhança, entra furtivamente numa argumentação que, aparentemente, não possui nenhuma relação com a anterior (a verossimilhança), mas é o efeito da causa da moraliza-

7 Grifo nosso.

8 “ $[\ldots]$ sequência de eventos da história, [...] linha que liga os pontos que desejamos mostrar e transpor. Essa linha não representa o material ou o conteúdo do romance - ou seja, o romance em si. Mas indica a distribuição, ao longo do texto, dos muitos milhares de pontinhos que compõem o romance". Pamuk, 2011, p. 6o. Ver também Moisés, 2004, p. 145-146. 
ção em exercício: ele começa a discutir a virtude; ele a conceitua como sendo o sacrifício de si mesmo. "O sacrifício que se faz a si mesmo em ideia é uma disposição preconcebida para imolar-se na realidade." (Diderot, 2000 , p. 17). Diderot acredita que o homem tem a disposição para a virtude e que essa disposição é desenvolvida pela educação.

Richardson semeia nos corações germes de virtude que aí remanescem de início ociosos e tranquilos: permanecem aí secretamente, até que se apresente uma ocasião que os remexa e os faça eclodir. Então eles se desenvolvem; sentimo-nos levados ao bem com uma impetuosidade que não sabíamos ter dentro de nós. Experimentamos, com o aspecto da injustiça, uma revolta que não poderíamos explicar a nós mesmos. É que frequentamos Richardson; é que conversamos com o homem de bem, em momentos em que a alma desinteressada estava aberta à verdade (Diderot, 2000, p. 17-18).

Diante de uma "alma desinteressada, e aberta à verdade", o autor deve, imperceptivelmente, adentrar o espírito do leitor/espectador para poder aí semear os “germes da virtude”, que serão revolvidos e remexidos, para então eclodir.

Se importa aos homens serem persuadidos de que, independentemente de toda consideração ulterior a esta vida, nós não temos nada de melhor a fazer para sermos felizes do que sermos virtuosos, que serviço não prestou Richardson à espécie humana? Ele não demonstrou de modo algum essa verdade; mas no-la fez sentir: a cada linha ele nos faz preferir a sorte da virtude oprimida à sorte do vício triunfante (Id., ibid., 18).

Diderot afirma ainda, nas linhas seguintes, que Richardson o ensinou a se tornar uma pessoa justa e imparcial, ao analisar as situações: "Se eu sei, malgrado os interesses que podem perturbar o meu julgamento, distribuir meu menosprezo ou minha estima segundo a justa medida da imparcialidade, é a Richardson que o 
devo" (Id., ibid., p. 19). Também o sentimento de comiseração é incitado pela leitura das obras de Richardson, uma vez que ele faz com que seu leitor se filie aos personagens que sofrem, compartilhe de sua dor: "em suas obras, como neste mundo, os homens estão divididos em duas classes: os que fruem e os que sofrem. É sempre a estes últimos que ele me associa; e, sem que eu me aperceba, o sentimento da comiseração se exerce e se fortifica" (Id., ibid.).

Ao chamar a atenção para o paralelo entre o enredo de Richardson e o mundo, Diderot ressalta um aspecto importante da questão, pois essa relação, esse paralelo, é uma das principais qualidades e características que possibilitam à literatura ser um instrumento para educar os homens. O realismo do enredo é responsável por transportar o leitor/espectador para a atmosfera do livro9.

Para defender Richardson das críticas que recebera na França, provavelmente de Voltaire ${ }^{10}$, centradas na quantidade supostamente exagerada dos detalhes nos romances do autor inglês, Diderot se queixa dos leitores/espectadores de seu tempo, afirmando que eles são arrastados por mil distrações e, por conta disso, não gostam de livros muito grandes, cheios de "detalhes inúteis", supostamente, desnecessários:

Entretanto, sejamos equânimes. Em um povo arrastado por mil distrações, onde não é bastante o dia em suas vinte e quatro horas para os divertimentos com que está acostumado a preenchê-las, os livros de Richard-

9 Diderot pode ser considerado o precursor dessa escola literária.

$10 \mathrm{O}$ autor das Cartas filosóficas não gostava do estilo de Richardson e entendia que sua obra era entediante, pois possuía detalhes desnecessários. Voltaire adotou o lado dos "antigos", e não dos "modernos" e, por esta razão, criticou Richardson, afirmando ser sua obra nove volumes inteiros nos quais não se encontra nada e dos quais o fizera perder seu tempo e o encadeamento dos seus estudos. (Cf. Lepape, 1991, p. 268). Sobre o que pensava Voltaire acerca dos livros de Richardson ver Santana, 2012. A crítica veemente que Diderot faz àqueles que reprovam Richardson por se alongar demais em seus romances, colocando muitos pormenores em seus enredos, dá-se pelo fato da crença de Diderot na eficácia desses pormenores: eles são responsáveis por colocar a "moral em exercício"; o leitor se torna espectador porque assiste à cena (Cf. Buffat, 1999, p. 158). 
son devem parecer longos. É pela mesma razão que esse povo já não tem mais ópera, e que incessantemente são representados em seus outros teatros somente cenas separadas de comédias e de tragédias. [...] Vós acusais Richardson de delongas! Haveis olvidado pois o quanto custa em esforços, desvelos, movimentos, fazer vingar a menor iniciativa, terminar um processo, concluir um casamento, conduzir uma reconciliação. Pensais destes detalhes o que vos aprouver; mas eles serão interessantes para mim, se forem verdadeiros, se fizerem sair as paixões, se mostrarem os caracteres (Diderot, 2000, p. 20).

Mais uma vez, encontramos a preocupação de Diderot com o realismo da descrição das cenas e a relação deste realismo com o efeito da moral colocada em prática; ou seja, o poder dessas descrições em "fazer saírem as paixões”, em "mostrar os caracteres" aparece no texto novamente. Não é em vão essa recorrência, uma vez que existe um paralelo fundamental entre a profusão de detalhes e o realismo da ação, e o efeito desta causa (o paralelo descrito) é a moralização colocada em atividade.

Eles são comuns, dizeis vós; é o que se vê todos os dias! Vós vos enganais; é o que se passa todos os dias sob vossos olhos e que não vedes jamais. Tomai cuidado; procedeis à condenação dos maiores poetas, sob o nome de Richardson. Vós haveis visto cem vezes o pôr-do-sol e o despontar das estrelas; vós tereis ouvido o campo retinir com o canto estrepitoso dos pássaros; mas quem de vós sentiu que era o rumor do dia que tornava o silêncio da noite mais tocante? Pois bem!, há para vós fenômenos morais assim como fenômenos físicos: os estrépitos das paixões feriram com frequência vossos ouvidos; mas vós estais bem longe de conhecer tudo o que há de secreto em seus acentos e em suas expressões. Não há nenhuma que não tenha sua fisionomia; todas essas fisionomias se sucedem em um semblante, sem que ele cesse de ser o mesmo; e a arte do grande poeta e a do grande pintor é a de vos mostrar uma circunstância fugidia que vos havia escapado. [...] Sabei que é a essa multidão de pequenas coisas que se prende a ilusão: há muita dificuldade para imaginá-las; há muito mais 
ainda para representá-las. O gesto é às vezes tão sublime quanto a palavra; e depois, são todas essas verdades de pormenor que preparam a alma para as impressões fortes dos grandes acontecimentos (Id., ibid.).

Na sequência desse raciocínio, Diderot usa a "moral em exercício" para levar seu leitor/espectador a entender o quão importante são os detalhes que tornam a obra de Richardson extensa. $\mathrm{O}$ panegirista pede a seu leitor/espectador que o imagine na seguinte situação: ele, o Philosophe, comprara um castelo, e visitando um dia os seus aposentos, percebe um armário que está fechado há muito tempo. Ao forçá-lo, ele descobre, dentro do armário, em total desordem, as cartas de Clarissa e Pâmela. Diderot informa ao seu leitor/espectador que teria, com presteza, ordenado as cartas e que ficaria desolado se percebesse alguma lacuna entre elas. Essa pequena narrativa é utilizada para criticar a edição francesa do texto de Richardson, traduzido pelo Abade Prévost, que suprimiu trechos e às vezes cenas inteiras para agradar ao gosto francês, que, como afirmado anteriormente, não se afeiçoou à obra, pela sua extensão e pela abundância de detalhes. ${ }^{12}$

Mas é precisamente por essas características que o romance surte efeito, por assim dizer, na imaginação do leitor. A literatura é eficaz na educação dos homens porque os instrui sem que os mesmos se apercebam disso; é o dulce et utile de Horácio. Essa característica da literatura possibilita ao leitor/espectador, após uma jornada de leitura, pensar de maneiras diferentes sobre aspectos da vida, sem que se dê conta de que houve um guia a efetuar essa transição, sem que se dê conta de que passara por uma experiência educativa, moral. O seu guia foram as ações das personagens, as escolhas diante dos problemas enfrentados por elas; o enredo

11 Grifo nosso. A literatura faz com que seu leitor/espectador enxergue coisas do cotidiano que ele não costuma observar e aprenda coisas das quais ele já sabia, sem se dar conta. 12 Cf. Id., ibid., p. 21. 
da obra literária; o texto em si, com suas marcas de estilo; o autor, com sua arte; o sentimento de humanidade, que permite aos leitores/espectadores se identificarem com as personagens: a literatura é universal, pois as sensações dos que dela usufruem pertencem aos seres humanos em geral'3.

Diderot compara a História ao romance de Richardson explicando que a primeira, apesar de verdadeira, está repleta de mentiras e o segundo, mesmo sendo fictício, está pleno de verdades. Pois enquanto a preocupação da História é contar os feitos de alguns indivíduos (deve-se levar em consideração a maneira como a História era feita no século XVIII, assim como é importante lembrar a crítica feita por Voltaire aos historiadores de sua época. O próprio Patriarca de Ferney, ao escrever Le Siècle de Louis XIV, propõe um novo método para a História ${ }^{14}$ ), os romancistas narram a história do gênero humano; os historiadores dão conta, em suas narrativas, de um ponto específico do globo terrestre, em um determinado tempo; os romancistas, de todo o globo, em todos os tempos.

Ó Richardson!, eu ousaria dizer que a história mais verdadeira está cheia de mentiras, e que teu romance está cheio de verdades. A história pinta alguns indivíduos: [sic] tu pintas a espécie humana; a história atribuiu a alguns indivíduos aquilo que eles não disseram, não fizeram: [sic] tudo o que atribuis ao homem, ele o disse e fez; a história abarca apenas uma porção da duração do tempo, apenas um ponto da superfície do globo; tu abarcastes todos os lugares e todos os tempos. O coração humano, que foi, é e sempre será o mesmo, é o modelo segundo o qual tu copias. Se se aplicasse ao melhor historiador uma crítica severa, haveria algum que a sustentasse como tu? Sob este ponto de vista, eu ousaria dizer que amiúde a história é um mau romance; e que o romance, como tu o fizeste,

${ }_{13}$ Cf. Pamuk, 2011, p. 41.

14 Sobre a concepção da História de Voltaire, ver tópico 4 (O exemplo da história) no capítulo "A filosofia desce à arena: o combate pelos costumes", em Mota, 2012. 
é uma boa história. Ó pintor da natureza!, és tu que não mentes jamais (Diderot, 2000, p. 23).

Dando continuidade ao passeio pelas páginas do Elogio, Diderot descreve numa passagem de seu texto que presenciara um amigo seu vivendo uma experiência de segunda mão ${ }^{15}$ ao ler Richardson. Ele descreve o momento em que este amigo recebera as cenas sobre o enterro e o testamento de Clarissa, duas passagens que foram suprimidas na tradução feita pelo Abade Prévost. Diderot explica que este amigo retirou-se para um canto e iniciou a leitura; que após algum tempo ele chorou, soluçou, levantou-se, caminhando sem saber para onde iria, lançou gritos como um homem desesperado e dirigiu exprobrações a toda família dos Harlove.

Eu estava com um amigo, quando me entregaram o enterro e o testamento de Clarisse, dois trechos que o tradutor francês suprimiu, sem que se saiba muito bem por quê. Este amigo é um dos homens mais sensíveis que eu conheço, e um dos mais ardorosos fanáticos de Richardson: falta pouco para que ele o seja tanto quanto eu. Ei-lo que se apodera dos cadernos, que se retira a um canto e que se põe a lê-los. Eu o examinava: primeiro eu vejo correr lágrimas, logo ele se interrompe, soluça: de repente, levanta-se, caminha sem saber aonde vai, lança gritos como um homem desolado, e dirige exprobrações das mais amargas a toda a família dos Harlove (Diderot, 2000, p. 26) ${ }^{16}$.

Uma passagem de O filho natural lembra esse trecho. No início dessa obra, Diderot explica que logo após ter acabado de

15 Entenda-se por experiência de segunda mão a própria moral sendo colocada em prática, visto que o leitor/espectador vive, sente, sofre, alegra-se com as personagens, a partir de suas vidas; ou seja, vive a partir das experiências de outrem; logo, de segunda mão.

16 Neste trecho, Diderot inverte os papéis entre ele e um amigo seu chamado Damilaville. 
publicar o sexto volume da Enciclopédia foi buscar retiro, tranquilidade e descanso no campo, especificamente em Massy, na casa de Le Breton, seu editor. Lá, conhecera Dorval, cuja descrição era feita pelas pessoas da região como sendo um "[...] homem incomum que, num mesmo dia, tinha tido a felicidade de arriscar a vida por um amigo e a coragem de sacrificar-lhe também paixão, fortuna e liberdade" (Diderot, 2008, p 28). Num segundo encontro com o mesmo Dorval, o Philosophe indagou-lhe a respeito de suas desventuras.

Ele respondeu às minhas perguntas. Contou sua história. Eu estremeci, com ele, diante das provações às quais o homem de bem se vê às vezes exposto e disse-lhe que uma obra dramática cujo tema fossem essas provações impressionaria todos aqueles que têm sensibilidade, virtude e noção da fraqueza humana (Id., ibid.).

Diderot encerra seu panegírico louvando Richardson e clamando aos séculos vindouros que deem a este autor as honras que ele merece e que não recebera em vida. Ele se vale assim de uma estratégia que pode ser considerada uma característica da emulação utilizada pela "moral em exercício": dirige-se ao leitor, em apóstrofe, o que dá a impressão de que o seu texto é compartilhado por este. Rompe-se o fluxo do Elogio. Diderot decsulpa-se então pelas linhas traçadas sem ligação com o precedente e justifica tal falha explicando que o gênio de Richardson sufocara o seu e que os fantasmas de suas personagens erraram em sua imaginação, atrapalhando-o de escrever ${ }^{17}$ Essa suposta desordem e negligência da parte de Diderot é uma estratégia para causar um determinado efeito em seu leitor/espectador. Ao afirmar que Richardson tem total domínio sobre seu público e sobre suas paixões, e ao mostrar-se como alguém que está arrebatado pela 
emoção, Diderot ganha força de argumentação para defender a superioridade de Richardson na arte de escrever romances.

Essa espécie de dissimulação, já antecipada no preâmbulo que os editores apresentaram sobre o Elogio, quando da sua publicação em 1762 no Journal Étranger, “[...] através da desordem e da negligência amável de um pincel que se abandona, reconhecemos facilmente a mão segura e sapiente de um grande pintor [...]" (Id., ibid., p. 16), confirma que Diderot, ao se deixar demonstrar como um leitor sensível, tomado pela emoção que o impede de escrever um texto ordenado; que estava, ao escrevê-lo, tomado pelas inspirações que eram ditadas pelos tumultos de seu coração; na verdade estava colocando em prática a sua estética; estava pondo a "moral em exercício", na tentativa de convencer seu leitor/ espectador acerca de um tema caro ao seu pensamento: a defesa de que a arte, de modo geral, e a literatura, de modo particular, possuem uma característica que as tornam carregadas de uma responsabilidade pública: elas são instrumentos eficazes de transmissão de valores caros à vida social; valores estes que tornam possível a felicidade individual e coletiva, uma vez que, como afirmara o próprio Diderot, não existe nada melhor para ser feliz do que ser virtuoso. E a virtude é possibilitada também através da arte, em particular, no caso da obra de Richardson, através da literatura.

\section{Referências bibliográficas}

BUFFAT, Marc. Éloge de Richardson. In: MORTIER, Roland; TROUSSON, Raymond. Dictionnaire de Diderot. Paris: Honoré Champion, 1999.

DIDEROT, Denis. Elogio a Richardson. In: Obras II: Estética, Poética e Contos. Trad. J. Guinsburg. São Paulo: Perspectiva, 2000 (Col. "Textos"). 
DIDEROT, Denis. Obras V: O filho natural. Trad. Fátima Saadi. São Paulo: Perspectiva, 2008 (Col. "Textos”).

FORSTER, E. M. Aspectos do romance. Trad. Sérgio Alcides. São Paulo: Globo, 2005.

LEPAPE, Pierre. Diderot. Paris: Champs/Flammarion, 1991.

MATTOS, Franklin de. "Moral em exercício". In: A cadeia secreta. São Paulo: Cosac Naify, 2004.

MOISÉS, Massaud. Dicionário de termos literários. São Paulo: Cultrix, 2004.

MOTA, Vladimir de Oliva. Acerca da noção de filosofia em Voltaire. Tese (Doutorado em Filosofia). Universidade de São Paulo - Faculdade de Filosofia, Letras e Ciências Humanas. São Paulo, 2012.

PAMUK, Orhan. "O que nossa mente faz quando lemos um romance". In: O romancista ingênuo e o sentimental. Trad. Hildegard Feist. São Paulo: Companhia das Letras, 2011.

RALLO, Elisabeth Ravoux. Métodos de crítica literária. Trad. Ivone C. Benedetti. São Paulo: Martins Fontes, 2005.

SANTANA, Christine Arndt de. "Voltaire e a "moral em exercício"”. In: . Educação e Literatura: a pedagogia por parágrafos em Voltaire. São Cristóvão: Editora UFS, 2012.

WILSON, Arthur. Diderot. Trad. Bruna Torlay. São Paulo: Perspectiva, 2012 (Col. Perspectivas). 
